\title{
MAGNETOELASTIC PROPERTIES OF SELECTED AMORPHOUS SYSTEMS TAILORED BY THERMOMAGNETIC TREATMENT
}

\author{
Peter Švec Sr. * - Roman Szewczyk ${ }^{* *}$ — Jacek Salach ${ }^{* *}$ - Dorota \\ Jackiewicz $^{* *}$ — Peter Śvec ${ }^{*}$ — Adam Bieńkowski ${ }^{* *}$ — Jozef Hoško ${ }^{*}$
}

\begin{abstract}
Magnetoelastic properties of $\mathrm{Fe}_{61} \mathrm{Co}_{19} \mathrm{Si}_{5} \mathrm{~B}_{15}$ alloy after thermomagnetic treatment were tested for both compressive and tensile stresses, what is significant novelty. Results of presented investigation opens new ways of modelling the magnetoelastic effects in amorphous systems tailored by thermomagnetic treatment.

K e y w or d s: magnetoelastic effect, Villari effect, amorphous alloys, thermomagnetic treatment
\end{abstract}

\section{INTRODUCTION}

Magnetoelastic properties are observed as the changes of flux density $B$, achieved for given value of magnetizing field $H$, under the influence of mechanical stresses [1], both compressive [2] and tensile [3]. This effect is very important from both theoretical and application point of view.

Theoretical analyses of magnetoelastic effect are connected with quantitative modelling of interaction of magnetic and mechanical processes. This interaction is especially visible in amorphous systems due to the lack of magnetocrystalline anisotropy [4]. Moreover, in amorphous magnetic alloys, the uniaxial anisotropy may be induced, during the magnetic field annealing [5]. As a result, the amorphous alloys are especially interesting magnetic materials for fundamental research on magnetoelasticity.

Magnetoelastic effect in amorphous alloys was widely investigated also due to its possible application in development extremely robust stress sensors, also for large diesel engines of locomotives [6]. However, until now, investigation on magnetoelastic properties of amorphous alloys tailored by thermomagnetic treatment was carried out in very limited way.

\section{THE MAGNETOELASTIC EFFECT}

Magnetoelastic Villari effect in magnetic materials is caused by changes of the total free energy of the material under influence of stresses caused by external forces. Value of energy of stress induced anisotropy is proportional to the value of the factor $\sigma \lambda_{s}$, where $\sigma$ is the stress in the material (noted as $\sigma$ for compressive stress and $+\sigma$ for tensile stress parallel to the magnetizing field $H)$ and $\lambda_{s}$ is the saturation magnetostriction $[7,8]$. The changes of the total free energy of the material can be experimentally observed as the changes of flux density B in the material. The typical changes of the flux density $B$ in material with negative, positive and nearly zero magnetostriction are presented in Fig. 1.

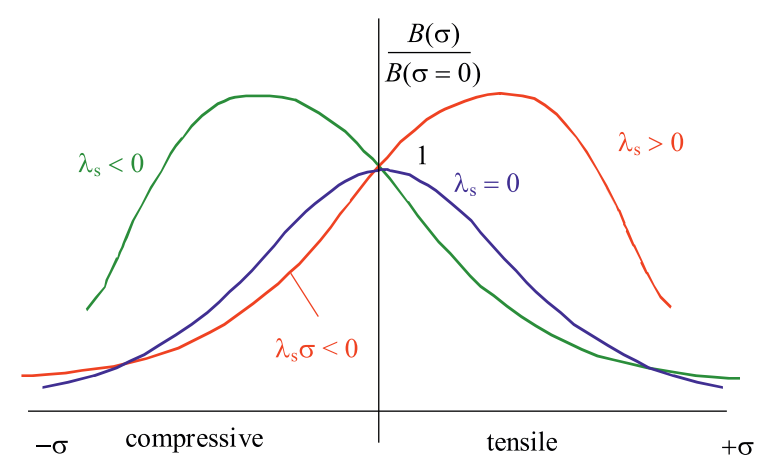

Fig. 1. Influence of compressive and tensile stresses on magnetic material with negative, positive and nearly zero magnetostriction

When under stresses value of $\sigma \lambda_{s}$ is negative, one can observe decreasing of value of flux density $B$. For positive value of $\sigma \lambda_{s}$ flux density increases. Moreover, the appearance of an extremum in the $B(\sigma)_{H}$ relation was detected and the point with $(\partial B / \partial \sigma)_{H}=0$ is called as the Villari point.

\section{SAMPLE PREPARATION}

Research was carried out on three ribbon ring cores made of $\mathrm{Fe}_{61} \mathrm{Co}_{19} \mathrm{Si}_{5} \mathrm{~B}_{15}$ amorphous alloy. Inside diameter was $25 \mathrm{~mm}$, outside diameter was $32 \mathrm{~mm}$, whereas height was $8 \mathrm{~mm}$. Samples were subjected to thermomagnetic treatment with use of specifically designed furnace. All cores were annealed in temperature $380^{\circ} \mathrm{C}$ for one hour. First core was annealed without magnetic field. Second and third core were annealed in magnetic field equal 200 $\mathrm{kA} / \mathrm{m}$ and $260 \mathrm{kA} / \mathrm{m}$ respectively.

\footnotetext{
* Institute of Physics, Slovak Academy of Sciences, peter.svec@savba.sk ${ }^{* *}$ Institute of Metrology and Biomedical Engineering, Warsaw University of Technology
} 


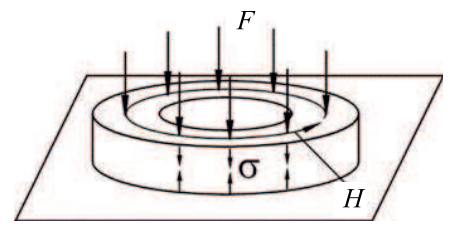

(a)

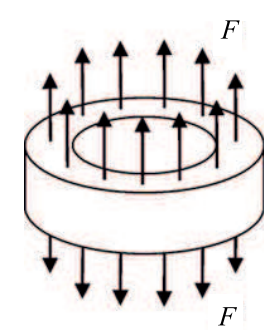

(b)
Fig. 2. An idea of generation of stresses: (a) - compressive, (b) - tensile

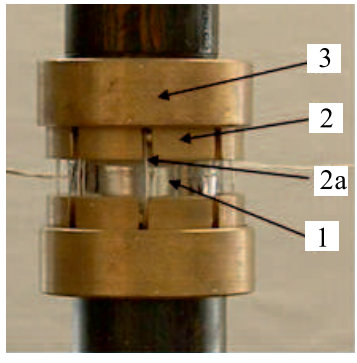

(a)

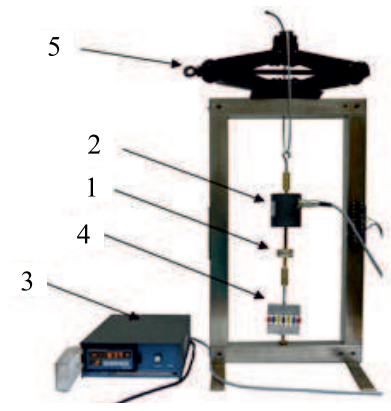

(b)
Fig. 3. Stress application systems: (a) - for compressive stresses: 1 base backings, 2 cylindrical, non-magnetic backings, 2a grooves for the winding, 3 investigated core, (b) - for tensile stresses: 1 amorphous ring shape core, 2 - precision force sensor together with 3 control equipment, 4 set of springs, 5 tensile force generator

\section{THE METHOD OF INVESTIGATION}

Idea of the method for generation of uniform compressive and tensile stresses in the ring shaped samples is presented in Fig. 2. In this method stresses occurs perpendicularly to the base of the ring core. The technical solution of mechanical systems for generation of compressive stresses uses set of specialized, nonmagnetic backings.

The device for applying compressive stresses to ring core [9] is presented in figure 3(a). This device allows core (1) to be winded and compressive force to be applied. Special cylindrical backings (2) made of nonmagnetic material are used. Between each backing (2) and the ring core special, elastic spacer is placed. In opposite to recently used methods [10] (especially suitable for amorphous wires), due to the use of ring-shaped core, the magnetic circuit of the sample is closed. As a result, stress sensitivity is not limited by demagnetization energy. Magnetizing and measuring windings are placed in special grooved races (2a) in backings. Compressive force $F$ is applied to device by base backings (3) placed in the ball joint.

Figure 3(b) shows view of the developed mechanical system for testing the influence of tensile stresses [11] on magnetic properties of ring shaped cores. Adjuster screw tensile stress (5) acts on the force sensor calibration (2) coupled with electronic processing (3) and tested the core (1). The system also provided a set of springs (4), which reduce the stiffness of the system.
As it was indicated, both compressive and tensile stresses are applied to the ring core perpendicularly to the base of the core $[9,11]$. As a result, the value of effective stress eff acting on the magnetization characteristics of the core can be determined from the relation [12]

$$
\sigma_{\text {eff }}=\sigma(\cos \varphi-\nu \sin \varphi)=-\nu \sigma
$$

where $\nu$ - is the Poison ratio of the material, $\varphi-$ the angle between the direction of the applied stress $\sigma$ and direction of the magnetizing field $H$ (in this case $\varphi=$ $90 \mathrm{deg}$.

\section{EXPERIMENTAL RESULTS}

The influence of both compressive and tensile stresses in the shape of hysteresis loops of $\mathrm{Fe}_{61} \mathrm{Co}_{19} \mathrm{Si}_{5} \mathrm{~B}_{15}$ amorphous alloy is presented in Fig. 4(a), 4(c) and 4(e), whereas magnetoelastic $B(\sigma)_{H}$ characteristics are presented in Fig.4 (b), 4(d) and 4(f).

Presented results are in the good qualitative agreement with general magnetoelastic effect theory presented in Fig. 1. Obviously, consequences of the equation 1 have to be taken into consideration. Moreover it should be taken into the account, that results of experiments presented in figure 5 are in good agreement with this theoretical analyse Lechatelier principle [14].

On the other hand, analyse presented above has only qualitative character. For quantitative magnetoelastic effect analyses, detailed physical principles modelling should be performed, considering also the value of uniaxial, thermomagnetic induced anisotropy. The model, which creates possibility of such quantitative analyse is expended Jiles-Atherton model [15]. Presented experimental results enable such novel, quantitative analyses based on theoretical models of magnetization process.

\section{CONCLUSION}

Presented results confirm usability of the presented method of magnetoelastic testing of ribbon ring-shaped cores for both compressive and tensile stresses. In presented methodology, the uniform stress distribution in the core is achieved, what creates possibility of theoretical analyses of magnetoelastic effect.

From qualitative point of view, presented results confirm general magnetoelastic effect theory as well as Lechatelier principle. Moreover, on the base of presented results, extended Jiles-Atherton model may be verified and developed considering uniaxial, thermomagneticaly induced anisotropy in $\mathrm{Fe}_{61} \mathrm{Co}_{19} \mathrm{Si}_{5} \mathrm{~B}_{15}$ VVamorphous alloy.

\section{Acknowledgements}

The support of the bilateral project APVV-Sk-PL0043-12 is acknowledged from Slovak side. Polish side (Institute of Metrology and Biomedical Engineering) was supported by statutory founds within Polish-Slovak bilateral cooperation. 


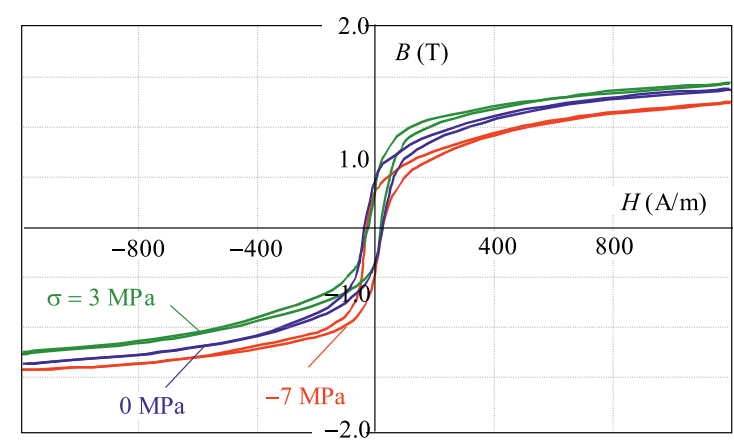

(a)

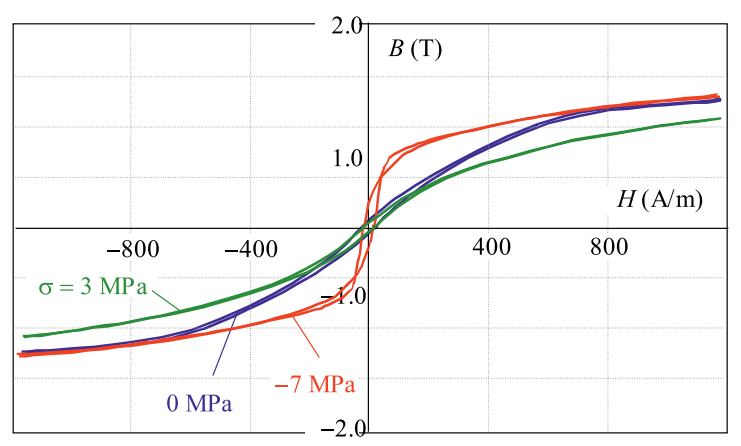

(c)

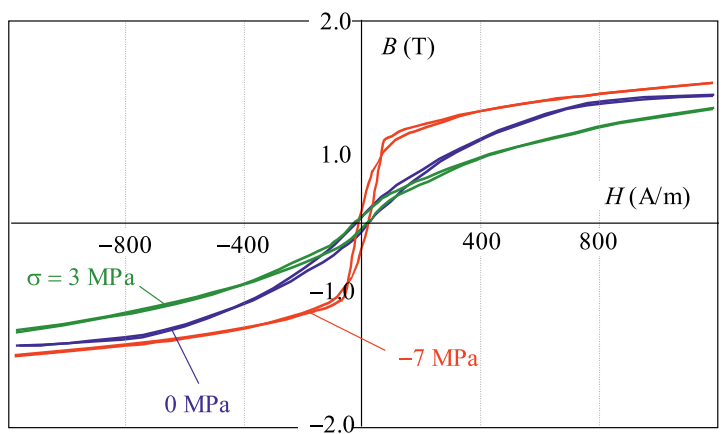

(e)

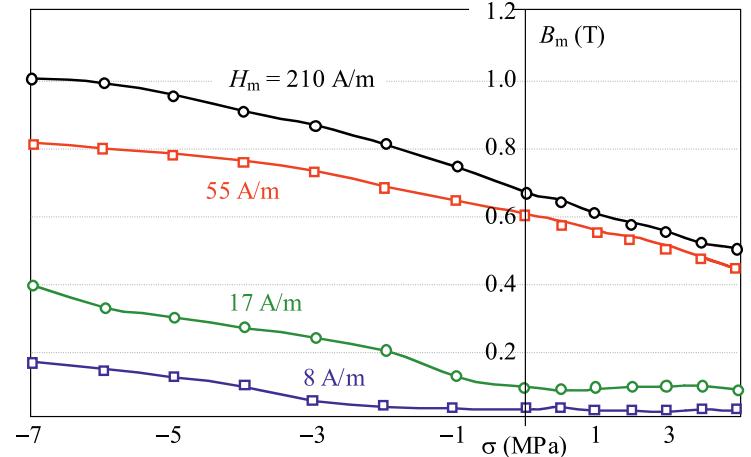

(b)

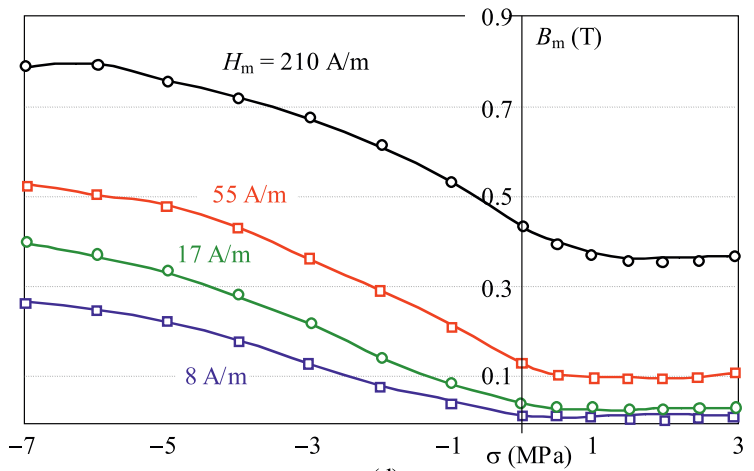

(d)

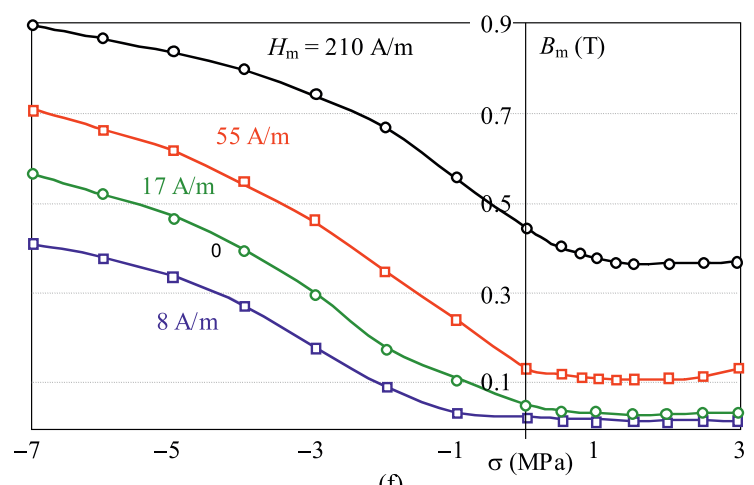

(f)

Fig. 4. Results of magnetoelastic tests of cores made of $\mathrm{Fe}_{61} \mathrm{Co}_{19} \mathrm{Si}_{5} \mathrm{~B}_{15}$ amorphous alloy annealed in $380{ }^{\circ} \mathrm{C} / 1$ hour: (a), (c), (e) - influence of compressive and tensile stresses $\sigma$ on $B(H)$ hysteresis loops of tested cores, (b), (d), (f) - magnetoelastic $B(\sigma)_{H}$ characteristics of cores, annealed at perpendicular field: (a), (b) $0 \mathrm{~A} / \mathrm{m}$, (c), q (d) $200 \mathrm{kA} / \mathrm{m}$, and (e), (f) $260 \mathrm{kA} / \mathrm{m}$

\section{REFERENCES}

[1] R. M. BOZORTH: Ferromagnetism, D. van Nostrood, New York (1956).

[2] BYDŽOVSKÝ, J.-KOLLÁR, M.-JANČÁRIK, V.- ŠSEC, P.-KRAUS, L.: Czechoslovak Journal of Physics 52A (2002) A117.

[3] SALACH, J.-SZEWCZYK, R.-BIEŃKOWSKI, A.-FRYDRYCH, P.: Journal of Electrical Engineering 61 (2010), 93.

[4] HASEGAWA, R.: Journal of Magnetism and Magnetic Materials 41 (1984), 79.

[5] ŠKORVÁNEK, IK.-MARCIN, J.-KRENICKÝ, T.-KOVÁC̆ J,- ک̌VEC, P.-JANIČKOVIČ, D. : Journal of Magnetism and Magnetic Materials 304 (2006), 203.

[6] BIEŃKOWSKI, A.-SZEWCZYK, R.-SALACH, J.: Acta Physica Polonica A 118 (2010), 1008.

[7] BIEŃKOWSKI, A.-KULIKOWSKI, J. : Journal of Magnetism and Magnetic Materials 19 (1980), 120.
[8] JEUN, M.-LIN, L.-JOO, H. W.-BAE, S.-HEO, J.-LEE, K. A. : Applied Physics Letters 94 (2009), 152512.

[9] BIEḰOWSKI, A.-SZEWCZYK, R. : Polish Patent P-345758 (2001).

[10] LIU, K. H.-LU, Z. C.-LIU, T. C.—LID. R. : Chinese Physics Letters 30 (2013), 017501.

[11] BIEḰOWSKI, A.-SZEWCZYK, R.-SALACH, J.: Polish Patent P-382457 (2007).

[12] SABLIK, M.-RUBIN, S.-RILEY, L.-JILES, D. C.-KAMINSKI, D.-BINER, S. : Journal of Applied Physics 74 (1993), 480.

[13] BOLL, R.-WARLIMONT, H. : IEEE Transactions on Magnetics 17 (1981) 3053.

[14] CULITY, B. D.: Introduction to magnetic materials, Wesley, (1972).

[15] SZEWCZYK, R.: Journal of Physics D Applied Physics 40 (2007), 4109

Received 11 September 2013 